Research Article

\title{
Characteristics of Annual and Seasonal Precipitation Variation in the Upstream of Minjiang River, Southwestern China
}

\author{
Shuqi Liang, ${ }^{1,2}$ Wensheng Wang $\mathbb{D}^{1,2}$ and Dan Zhang ${ }^{1,2}$ \\ ${ }^{1}$ School of Water Resource and Hydropower, Sichuan University, 610065 Chengdu, China \\ ${ }^{2}$ State Key Laboratory of Hydraulics and Mountain River Eng., Sichuan University, 610065 Chengdu, China \\ Correspondence should be addressed to Wensheng Wang; wangws70@scu.edu.cn
}

Received 8 June 2018; Revised 21 August 2018; Accepted 26 September 2018; Published 30 October 2018

Academic Editor: Anthony R. Lupo

Copyright (c) 2018 Shuqi Liang et al. This is an open access article distributed under the Creative Commons Attribution License, which permits unrestricted use, distribution, and reproduction in any medium, provided the original work is properly cited.

Characteristics of annual and seasonal precipitation variation are explored in the upstream of Minjiang River (UMR), Southwestern China, spanning from 1960 to 2015. The moment of method (MOM), linear regression method, Mann-Kendall test, sequential cluster analysis, and Morlet wavelet analysis were utilized. The results clearly show the following: (1) Distribution of precipitation is uneven in space, with more in the south and less in the southeast. Decade average of annual precipitation reached the lowest in the 2000s and increased during 2010-2015 at all gauging stations and UMR. (2) Areal annual precipitation exhibited an insignificant decreasing trend with a rate of $4.47 \mathrm{~mm} / 10 \mathrm{a}$, which was mainly attributable to decreased summer precipitation. Spring precipitation exhibited an insignificant increasing trend and winter precipitation remained unchanged. (3) The change points mainly appeared in the 1980s and 1990s. And the almost periods of study area were generally $2-5$ years, 7-11 years, and 15-20 years. (4) The increasing trend of annual precipitation is relatively obvious at higher altitudes, while the decreasing trend is more significant at low altitude stations.

\section{Introduction}

The issue of global climate change has become increasingly prominent, which is one of the world-wide problems that should be faced during economic and social development [1-3]. As is known to all, climate change has a relatively large influence on changes in meteorological factors such as temperature and precipitation. In recent years, the precipitation of China has changed abnormally under climate change condition [4-6]. Changes in the precipitation pattern may lead to droughts, floods, soil erosion, and loss of biodiversity and agricultural productivity. Hence, analyzing statistical properties of precipitation plays a crucial role not only in drought and flood risk assessments but also in water resources planning and management.

Trend analysis and abrupt change detection in hydrometeorological time series have been investigated using statistical methods by many researchers [7-15]. Sayemuzzaman et al. [16] utilized the Mann-Kendall test and the Theil-Sen approach to detect the trends of annual and seasonal precipitation sequences in time and space across the state of North Carolina, United States. Shirvani [17] detected the change point in the annual Persian Gulf sea surface temperature anomalies time series during 1951-2013 based on Student's $t$ parametric and Mann-Whitney nonparametric change point models. Zarenistanak et al. [18] analyzed trends and change points of annual and seasonal precipitation and temperature series over southwest Iran with Pettitt's test, Mann-Kendall test spanning from 1950 to 2007.

The wavelet method has good time and frequency multiresolution, which can effectively diagnose the main frequency component and abstract local information of the time series. Some researchers have applied wavelet analysis to investigate the periods of time series such as runoff, precipitation, and temperature [19-21]. Jemai et al. [22] revealed the periods of rain in Gabes Basin based on wavelet and coherence wavelet analyses. Sang et al. [23] used the improved continuous wavelet transform method to study the periodic characteristics of several typical hydrological series, including runoff and precipitation data. 
Due to the impact of climate change, the frequency and intensity of droughts and floods in the southwest of China have been increasing $[24,25]$. As one of the core areas of southwest China, the UMR, located in the transitional area between the Qinghai-Tibet Plateau and the Sichuan Basin, is the main source of water for Chengdu plain, and its runoff is mainly recharged from precipitation. However, frequent droughts and floods in this area have hindered its economic development and resulted in severe environmental problems [26]. Thus, the study of hydrological and meteorological variation characteristics in the UMR is increasingly being paid more and more attention. Huang et al. [27] detected the characteristics of hydroclimatic change in the UMR based on seven hydrological stations and six meteorological stations over 1956-2007, including precipitation, temperature, and runoff. The results indicated that there was a significant decreasing trend in precipitation, a significant increasing trend in annual average temperature, and a significant decreasing trend in total runoff. Zhou et al. [28] explored the spatial and temporal distribution of precipitation in Minjiang River Basin from 1956 to 2001 and revealed that precipitation in flood season presented a decreasing trend, and its periodic variations are 2 years, 5-7 years, and 14-15 years. Ma et al. [29] analyzed trends and abrupt changes of monthly and annual average temperature and precipitation of Songpan County. To the best of our knowledge, previous studies are almost before 2010 and do not cover the entirety of UMR as a study area to systematically and deeply detect precipitation variation.

The key objective of this study is to investigate the spacetime distribution, trends, abrupt changes, and periods of precipitation in the UMR by using historical observed daily precipitation from 1960 to 2015 at annual and seasonal time scale. At the same time, the cause of precipitation change is also discussed. Such a study is beneficial for reducing the risk of disaster, reasonably allocating water resources, and supporting the decisions of water resource management under climate change condition. It also plays a crucial role in providing a reliable basis for government decision-making and helping the regional social and economic sustainable development. After Introduction, the study area and the selected data are given in Section 2. Section 3 lists the appropriate methodology. In Section 4, the obtained results are presented and discussed. Finally, conclusions are summarized in Section 5.

\section{Study Area and Data}

2.1. Study Area. As one of the major tributaries of the Yangtze River in China, Minjiang River originates in the southern part of Minshan Mountain on the border between Sichuan and Gansu provinces, crosses Chengdu Plain, and runs into the Yangtze River from Yibin city. The upstream of Minjiang River (UMR) refers to the river above Zipingpu Reservoir, which is a plateau climate and subtropical climate region. It stretches from longitude $102^{\circ} 45^{\prime} \mathrm{E}$ to $103^{\circ} 96^{\prime} \mathrm{E}$ and from latitude $30^{\circ} 80^{\prime} \mathrm{N}$ to $33^{\circ} 20^{\prime} \mathrm{N}$. It covers an area of approximately $23000 \mathrm{~km}^{2}$ (16.9\% of the entire Minjiang Basin), and the river course is $341 \mathrm{~km}$ long. The location of the study area is shown in Figure 1.

2.2. Data. There are five meteorological stations (Maoxian, Songpan, Wenchuan, Lixian, and Heishui) and one hydrological station (Zipingpu) available within the study basin, and they are distributed over the study area as shown in Figure 1. Detailed information regarding the stations is summarized in Table 1. Daily precipitation data of above 6 gauging stations were collected from the China Meteorological Data Sharing Service System and the Bureau of Hydrology and Water Resources of Sichuan Province from the period 1960 to 2015 . The little missing data were interpolated by linear regression of the adjacent station data. Daily values were summed up to obtain seasonal and annual totals of precipitation. Areal precipitation was obtained by the Thiessen polygon method. The season in a year was defined as follows: winter (December, January, and February), spring (March, April, and May), summer (June, July, and August), and autumn (September, October, and November).

\section{Methodology}

3.1. Statistical Parameters Estimated Based on MOM. The statistical parameters, mean and deviation coefficient $\left(C_{v}\right)$ of seasonal and annual precipitation, have been estimated with the moment of method (MOM) [30]. The formulas of MOM are not listed here.

\subsection{Trend Detection Method}

3.2.1. Linear Regression Method. The linear regression method is extensively used to determine the trend of climatic series [31]. In this study, unitary linear equation about precipitation to time is expressed as

$$
x=a+b \cdot t
$$

where $t$ is the time variable, $x$ is the observed precipitation value at time $t, a$ is a constant, and $b$ is the slope which denotes the change rate. In detail, a positive value of $b$ indicates an increasing trend, and a negative value of $b$ indicates a decreasing trend. We used Student's $t$-test to examine the significance level of parameter $b$, and the details are not listed here.

3.2.2. Mann-Kendall Test of Trend. The nonparametric Mann-Kendall (MK) test $[32,33]$ has been widely used to diagnose trends in time series. The statistic $S$ of MK test is defined as

$$
S=\sum_{i=1}^{n-1} \sum_{j=i+1}^{n} \operatorname{sgn}\left(x_{i}-x_{j}\right)
$$

where $x_{i}$ and $x_{j}$ are the observed precipitation values at time $i$ and $j$, respectively, $n$ is the length of the data, and $\operatorname{sgn}()$ is the sign function. 


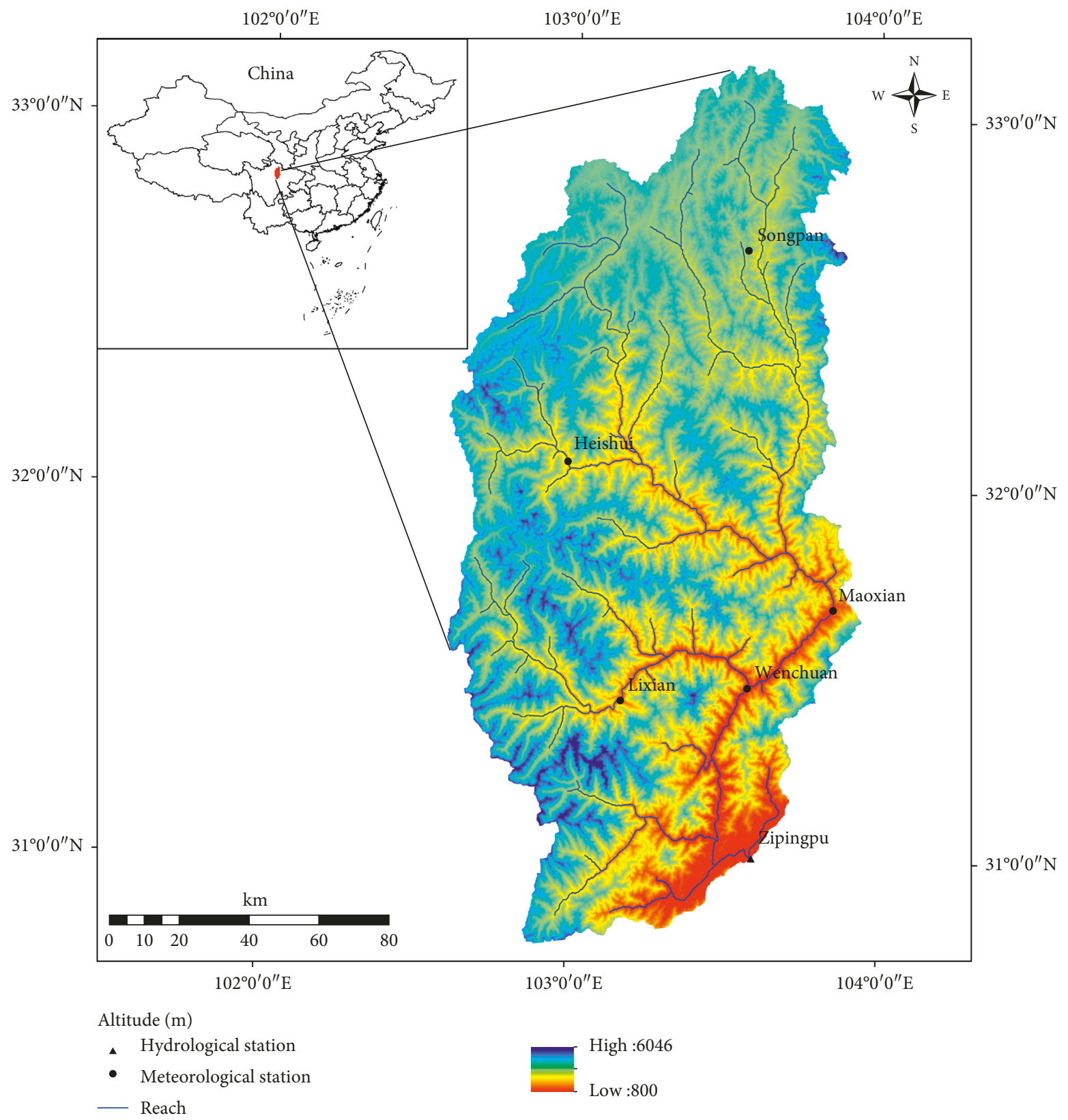

FIgURE: 1: Location of study area and gauging stations.

TABLE 1: Detailed information of gauging stations.

\begin{tabular}{|c|c|c|c|c|c|}
\hline Station & River & Longitude $\left({ }^{\circ} \mathrm{E}\right)$ & Latitude $\left({ }^{\circ} \mathrm{N}\right)$ & Data period & Annual precipitation $(\mathrm{mm})$ \\
\hline Maoxian & Minjiang & 103.85 & 31.68 & 1960-2015 & 475 \\
\hline Songpan & Minjiang & 103.57 & 32.65 & 1960-2015 & 720 \\
\hline Wenchuan & Minjiang & 103.58 & 31.47 & 1960-2015 & 506 \\
\hline Lixian & Zagunao & 103.17 & 31.43 & 1960-2015 & 620 \\
\hline Heishui & Heishui & 102.98 & 32.08 & 1960-2015 & 828 \\
\hline Zipingpu & Minjiang & 103.34 & 31.02 & 1960-2015 & 1179 \\
\hline
\end{tabular}




$$
\operatorname{sgn}\left(x_{i}-x_{j}\right)=\left\{\begin{array}{lc}
1 & \text { if } x_{i}>x_{j}, \\
0 & \text { if } x_{i}=x_{j} \\
-1 & \text { if } x_{i}<x_{j} .
\end{array}\right.
$$

The variance of $S$ and the test statistic $Z$ are calculated as follows:

$$
\begin{aligned}
\operatorname{var}(S) & =\frac{n(n-1)(2 n+5)-\sum_{t} t(t-1)(2 t+5)}{18}, \\
Z & = \begin{cases}(S-1) / \sqrt{\operatorname{var}(S)}, & \text { if } S>0, \\
0, & \text { if } S=0, \\
(S+1) / \sqrt{\operatorname{var}(S)}, & \text { if } S<0,\end{cases}
\end{aligned}
$$

A positive value of $Z$ indicates an increasing trend; a negative value of $Z$ indicates a decreasing trend. If $|Z|<$ $Z_{1-\alpha / 2}$, the null hypothesis is accepted, and the trend is not significant. The null hypothesis is rejected at the $\alpha$-significance level if $|Z| \geq Z_{1-\alpha / 2}$. When the $\alpha$-significance level is 0.05 , the corresponding value of $Z_{1-\alpha / 2}$ is 1.96 .

In the MK test of trend, another useful index is the Kendall slope, $\beta$, which is an unbiased estimator of monotonic trend magnitude:

$$
\beta=\operatorname{media}\left(\frac{x_{i}-x_{j}}{i-j}\right),
$$

where $1<i<j<n$. A positive slope value $(\beta>0)$ denotes an increasing trend; a negative slope value $(\beta<0)$ denotes a decreasing trend.

\subsection{Test Method of Abrupt Change}

3.3.1. Mann-Kendall Test of Abrupt Changes. A rank series is constructed for a time series $x$ with $n$ samples [34, 35]:

$$
d_{k}=\sum_{i=1}^{k} m_{i} \quad(2 \leq k \leq n)
$$

where

$$
m_{i}=\left\{\begin{array}{ll}
+1, & x_{i}>x_{j}, \\
0, & x_{i} \leq x_{j},
\end{array} \quad(1 \leq j \leq i, \quad 1 \leq i \leq n) .\right.
$$

$d_{k}$ can be considered as normal distribution under the null hypothesis $H_{0}$ that a trend does not occur, and the mean and variance of $d_{k}$ can be calculated as follows:

$$
\begin{aligned}
E\left(d_{k}\right) & =\frac{k(k-1)}{4}, \\
D\left(d_{k}\right) & =\frac{k(k-1)(2 k+5)}{72} .
\end{aligned}
$$

The statistic $\mathrm{UF}_{k}$ is computed by

$$
\mathrm{UF}_{k}=\frac{d_{k}-E\left(d_{k}\right)}{\sqrt{D\left(d_{k}\right)}} \quad(1 \leq k \leq n)
$$

In order to search an abrupt change, it is necessary to perform a similar analysis on the reverse time series. A retrograde $\mathrm{UB}_{k}$ is expressed as

$$
\mathrm{UB}_{k}=-\mathrm{UF}_{k^{\prime}}, k^{\prime}=n+1-k \quad\left(k, k^{\prime}=1,2, \cdots, n\right) .
$$

The intersection point of $\mathrm{UF}_{k}$ and $\mathrm{UB}_{k}$ located between the confidence lines is the time when an abrupt change takes place. A typical confidence level of $95 \%$ is utilized in the detection of the precipitation series.

3.3.2. Sequential Cluster Analysis. Sequential cluster analysis is an effective method for estimating the abrupt change point $\tau$ in hydrological time series. The essence of sequential cluster analysis is to find the optimal split point $[36,37]$. The objective function is calculated as

$$
S=\min _{2 \leq \tau \leq n-1}\left\{S_{n}(\tau)=\sum_{i=1}^{\tau}\left(x_{i}-\bar{x}_{\tau}\right)^{2}+\sum_{i=\tau+1}^{n}\left(x_{i}-\bar{x}_{n-\tau}\right)^{2}\right\},
$$

in which, $\bar{x}_{\tau}=(1 / \tau) \sum_{i=1}^{\tau} x_{i}, \bar{x}_{n-\tau}=(1 / n-\tau) \sum_{i=\tau+1}^{n} x_{i}$.

When $S$ is the minimum value, its corresponding $\tau$ is the optimal split point, which is the most likely change point.

3.4. Morlet Wavelet Analysis. Wavelet analysis is employed to detect the periods of time series [37]. For time series $f(t)$, the continuous wavelet transform is calculated as

$$
W_{f}(a, b)=|a|^{-(1 / 2)} \int_{-\infty}^{+\infty} f(t) \bar{\psi}\left(\frac{t-b}{a}\right) d t \quad a, b \in R, a \neq 0,
$$

where $W_{f}(a, b)$ is the wavelet transform coefficient, $\psi(t)$ is the mother wavelet, $\bar{\psi}(t)$ is the complex conjugate functions of $\psi(t), a$ is the scale factor, and $b$ is a time parameter. In this study, we have chosen Morlet wavelet function to be the mother wavelet. The Morlet wavelet function is expressed as

$$
\psi(t)=e^{\mathrm{ict}} e^{-t^{2} / 2}
$$

\section{Results and Discussion}

4.1. Variation of Basic Statistical Parameters. Basic statistical parameters (mean and $C_{\mathrm{v}}$ ) of annual and seasonal (spring, summer, autumn, and winter) precipitation are obtained for 6 gauging stations and the UMR during the period of 56 years (Table 2).

On the annual basis, precipitation in the UMR is uneven spatially and increases from the northeast to southwest for both upstream and downstream (Figure 2(e)); the maximum value of mean precipitation is obtained at Zipingpu $(1179 \mathrm{~mm})$ in the south, and minimum value of mean precipitation is obtained at Maoxian $(475 \mathrm{~mm})$ in the southeast. The $C_{v}$ varies from 0.11 (Songpan) to 0.20 (Zipingpu) with average value 0.10 of the entire basin, which indicates that interannual variation is stable in the study area (Figure 3). Figure 4 presents the decadal variation of annual precipitation. The mean annual precipitation of UMR was 
TABLE 2: Statistical parameters of seasonal and annual precipitation.

\begin{tabular}{|c|c|c|c|c|c|c|c|c|}
\hline \multicolumn{2}{|c|}{ Region or station } & \multirow{2}{*}{$\begin{array}{c}\text { Maoxian } \\
132\end{array}$} & \multirow{2}{*}{$\begin{array}{c}\text { Songpan } \\
205\end{array}$} & \multirow{2}{*}{$\begin{array}{c}\text { Wenchuan } \\
141\end{array}$} & \multirow{2}{*}{$\begin{array}{c}\text { Lixian } \\
183\end{array}$} & \multirow{2}{*}{$\begin{array}{c}\text { Heishui } \\
224\end{array}$} & \multirow{2}{*}{$\begin{array}{c}\text { Zipingpu } \\
203\end{array}$} & \multirow{2}{*}{$\begin{array}{c}\text { UMR } \\
186\end{array}$} \\
\hline Snring & $\operatorname{Mean}(\mathrm{mm})$ & & & & & & & \\
\hline spring & $C_{\mathrm{v}}$ & 0.21 & 0.20 & 0.19 & 0.19 & 0.19 & 0.25 & 0.15 \\
\hline \multirow{2}{*}{ Summer } & $\operatorname{Mean}(\mathrm{mm})$ & 230 & 302 & 239 & 256 & 375 & 647 & 302 \\
\hline & $C_{\mathrm{v}}$ & 0.25 & 0.17 & 0.22 & 0.22 & 0.19 & 0.34 & 0.16 \\
\hline \multirow{2}{*}{ Autumn } & $\operatorname{Mean}(\mathrm{mm})$ & 103 & 191 & 116 & 156 & 211 & 279 & 173 \\
\hline & $C_{\mathrm{v}}$ & 0.24 & 0.23 & 0.24 & 0.24 & 0.22 & 0.35 & 0.19 \\
\hline \multirow{2}{*}{ Winter } & $\operatorname{Mean}(\mathrm{mm})$ & 10 & 22 & 10 & 24 & 18 & 49 & 19 \\
\hline & $C_{\mathrm{v}}$ & 0.39 & 0.35 & 0.52 & 0.36 & 0.41 & 0.33 & 0.28 \\
\hline \multirow{2}{*}{ Annual } & $\operatorname{Mean}(\mathrm{mm})$ & 475 & 720 & 506 & 620 & 828 & 1179 & 680 \\
\hline & $C_{\mathrm{v}}$ & 0.14 & 0.11 & 0.13 & 0.13 & 0.12 & 0.20 & 0.10 \\
\hline
\end{tabular}

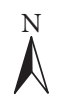

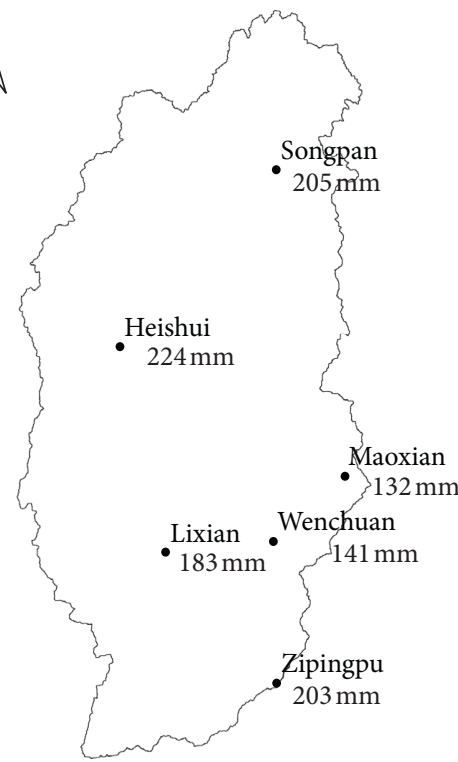

(a)

$\stackrel{N}{N}$

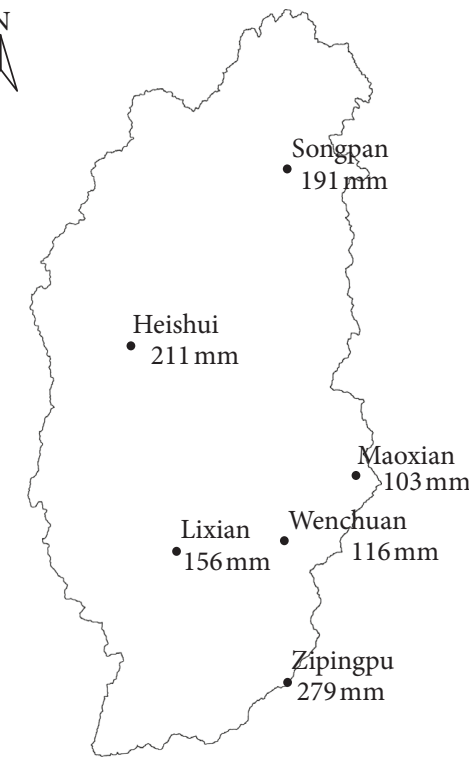

(c)

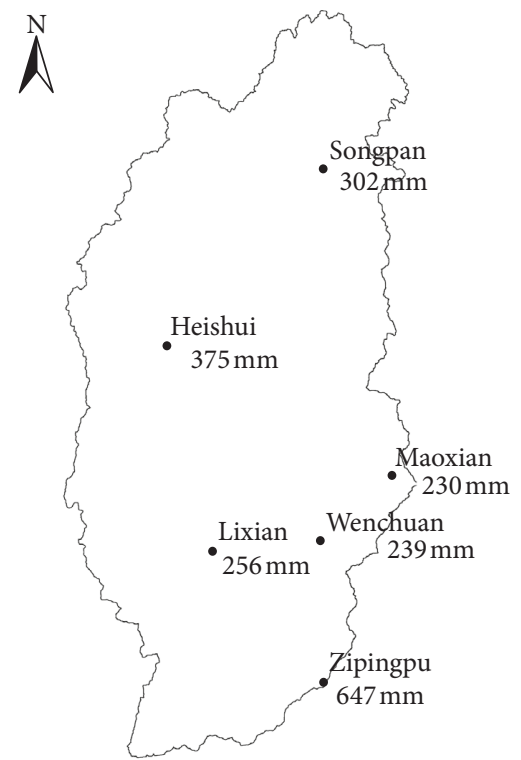

(b)

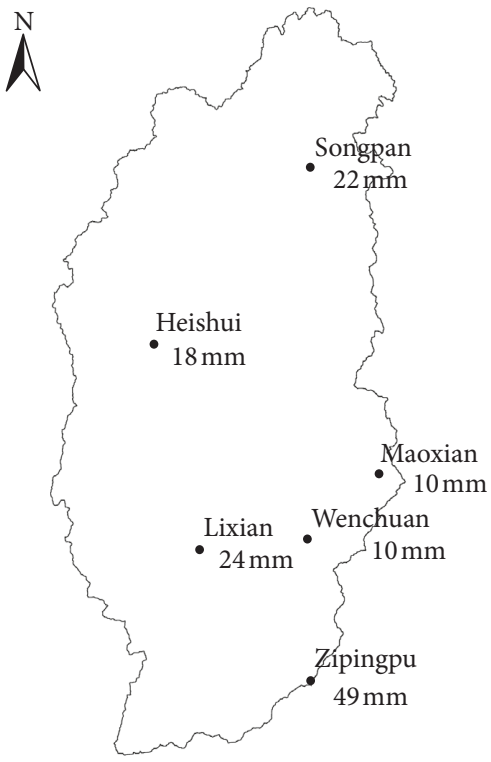

(d)

Figure 2: Continued. 


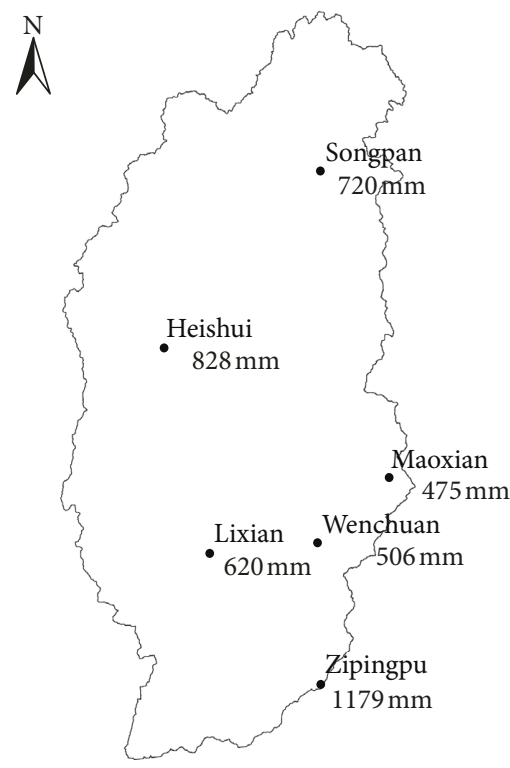

(e)

FIGURE 2: Spatial distributions of precipitation in the UMR (a) spring (b) summer (c) autumn (d) winter and (e) annual.

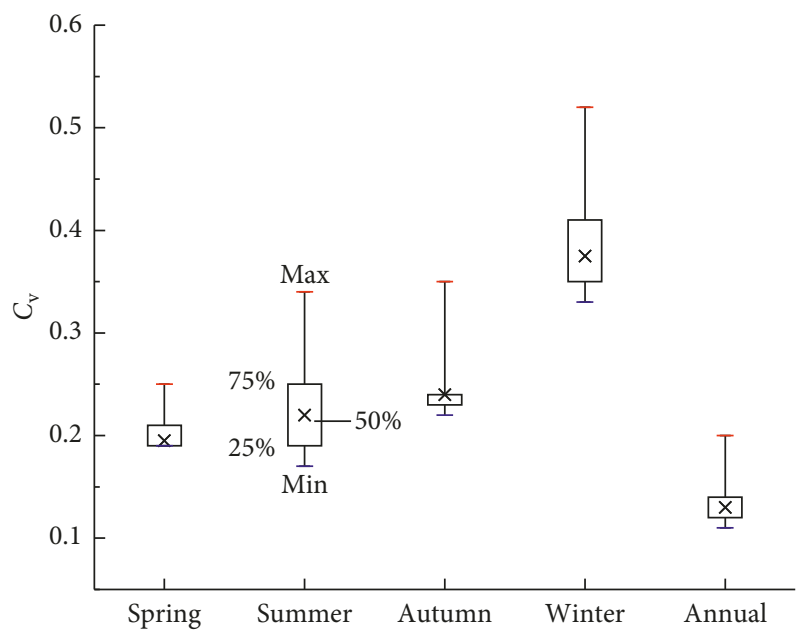

FIgURE 3: Box diagram of $C_{\mathrm{v}}$ at 6 stations in UMR from 1960-2015.

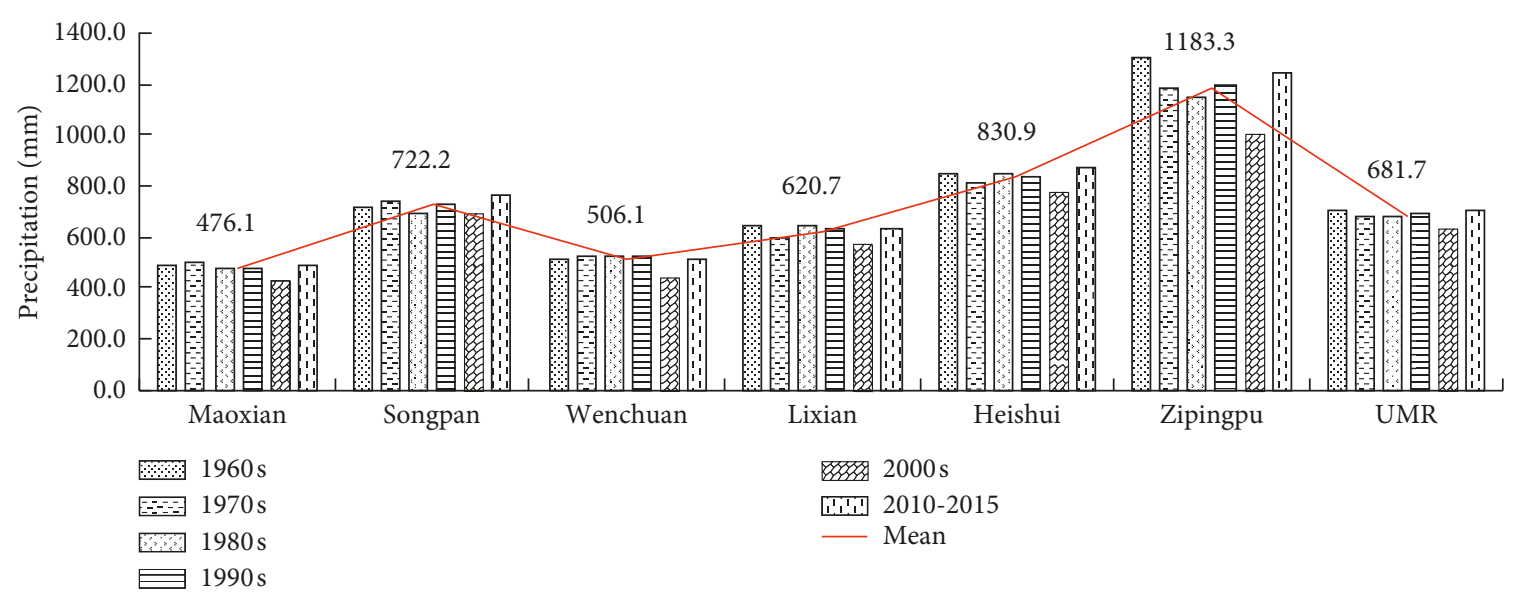

FIGURE 4: Variation of decade mean annual precipitation in gauging stations and UMR. 
higher in the 1960s, 1980s, 1990s, and 2010-2015 and lower in the 1970s and 2000s. Especially, in the 2000s, mean annual precipitation reached the lowest value, nearly $47.8 \mathrm{~mm}$ lower than $680 \mathrm{~mm}$ of the interannual level. During 2010-2015, it reached the highest value, $22.8 \mathrm{~mm}$ higher than the average value in the studied period, which is consistent with the corresponding studies [38]. Moreover, the decade average precipitation reached the lowest in the 2000s and increased during 2010-2015 at all gauging stations. A preliminary conclusion was drawn that the precipitation in the study area was relatively abnormal after the 21st century.

Space distribution of seasonal precipitation is uneven, with more in the south and less in the southeast (Figure 2(a)-2(d)). Mean values of precipitation vary from $132 \mathrm{~mm}$ (Maoxian) to $224 \mathrm{~m}$ (Heishui) in spring, from $230 \mathrm{~mm}$ (Maoxian) to $647 \mathrm{~mm}$ (Zipingpu) in summer, from $103 \mathrm{~mm}$ (Maoxian) to $279 \mathrm{~mm}$ (Zipingpu) in autumn, and from $10 \mathrm{~mm}$ (Maoxian ands Wenchuan) to $49 \mathrm{~mm}$ (Zipingpu) in winter. We can conclude that the intraannual variation of annual precipitation is inhomogeneous with lager difference in four seasons; summer precipitation is the most and winter precipitation is the least. $C v$ ranges from 0.19 (Wenchuan, Lixian, and Heishui) to 0.25 (Zipingpu) in spring, 0.17 (Songpan) to 0.34 (Zipingpu) in summer, 0.22 (Heishui) to 0.35 (Zipingpu) in autumn, and 0.33 (Zipingpu) to 0.52 (Wenchuan) in winter. It is obvious that the interannual variations of seasonal precipitation are different; the change is the largest in winter, following autumn, summer and spring (Figure 3).

\subsection{Trend Analysis}

4.2.1. Trends Based on Linear Regression Method. The $b$ values of linear regression method are listed in Table 3 . On the annual basis, the precipitation series of the entire basin showed an insignificant decreasing trend with a rate of $-5.61 \mathrm{~mm} / 10 \mathrm{a}$, and large fluctuations occurred in the 1970s and 2000s (Figure 5(e)). For seasonal scale, an insignificant increasing trend was found in spring and winter precipitation series. In summer and autumn, the areal precipitation series had an insignificant decreasing trend.

4.2.2. Trends Based on MK Test. The MK test was utilized to determine the trend using two-tailed hypothesis at 5\% significant levels. The MK test results $(Z)$ along with the magnitude of trend $(\beta)$ are presented in Table 3. Comparing with the linear regression method, their results are almost consistent. Box diagram of $Z$ at 6 stations is displayed in Figure 6.

For annual scale, areal precipitation showed an insignificant decreasing trend, and the Kendall slope was $-4.47 \mathrm{~mm} / 10 \mathrm{a}$, which was consistent with the previous studies $[28,38,39]$. A significant decreasing trend was only found at Zipingpu station. Analyzing the precipitation series on seasonal scale, areal precipitation displayed an insignificant increasing trend in spring $(\beta=3.45 \mathrm{~mm} / 10 \mathrm{a})$; an insignificant decreasing trend in summer $(\beta=-8.00 \mathrm{~mm} / 10 \mathrm{a})$ and autumn $(\beta=-3.60 \mathrm{~mm} / 10 \mathrm{a})$ [40]. In comparison with other seasons, winter precipitation was relatively stable with little annual variability at a rate of $0.35 \mathrm{~mm} / 10 \mathrm{a}$ in the past 56 years. Comprehensive analysis leads to the conclusion that the decreased annual precipitation was mainly attributable to decreased summer precipitation in the upstream of Minjiang River [27]. There was a significant increasing trend of spring precipitation at Songpan station and a significant decreasing trend of summer precipitation at Maoxian, Wenchuan, and Zipingpu stations.

\subsection{Abrupt Changes Based on Sequential Cluster Analysis.} Detecting the precipitation change point is an essential step that can enable a better interpretation and more accurate forecasts of hydrological data. The change points of the annual and seasonal precipitation time series are presented in Table 4. Parts of diagnosed graphs are given in Figure 7.

For annual precipitation of UMR, there were several intersections between the UF and UB series in the 1980s and 1990s (Figure 7(e)); and the optimal split point was in 1995 (Figure $7(\mathrm{j})$ ). Although the diagnosis results are not same, it is more appropriate to divide the year of abrupt change into around 1995. The mean precipitation was $693 \mathrm{~mm}$ during 1960-1995 and decreased to $657 \mathrm{~mm}$ during 1996-2015. Therefore, the results of MK test of abrupt change and sequential cluster analysis indicated that there was a sudden decrease in annual precipitation around 1995 [41]. As for spring precipitation of UMR, the intersection between the UF and UB series was in 2001, but the optimal split point was in 1995. There was a large difference of time-interval, so we believed that no abrupt change occurred. The abrupt change result of winter precipitation was the same as spring. By selecting the same point of two methods, the change points took place in 1994 during summer, in 1976 during autumn. In sum, the change points mainly appeared in the 1980s and 1990s, which was similar to the past studies [35].

There exists certain degree of abrupt changes of the annual and seasonal precipitation series; and change points show different characteristics among different gauging stations and UMR. Such spatial variability might be derived from the different natural topography, geographical location, and anthropic activities in the study area. And the specific reasons need to be further analyzed.

4.4. Periods Based on Morlet Wavelet Analysis. The periodic fluctuation of precipitation results in the up and down of runoff, so it is important to correctly understand the periodic variation of precipitation. Morlet wavelet analysis was used to identify periods of precipitation series. And the results are listed in Table 5. Time frequency graphs of wavelet transform in UMR are presented in Figure 8.

As shown in Figure 8(e), the time parameter $b$ is the abscissa, and the frequency parameter $a$ is the ordinate. The upper part is low frequency, and the isolines are relatively sparse, which corresponds to a long period of oscillation. The lower part is high frequency, and the isolines are relatively dense, which corresponds to a shorter scale cycle. It can be seen that areal annual precipitation had periods of 2, 5, and 17 years. The almost periods of seasonal precipitation were 2 , 
TABLE 3: Values of $b$ in linear regression analysis and $Z$ and $\beta$ in MK of UMR.

\begin{tabular}{|c|c|c|c|c|c|c|c|c|}
\hline \multicolumn{2}{|c|}{ Region or station } & Maoxian & Songpan & Wenchuan & Lixian & Heishui & Zipingpu & UMR \\
\hline \multirow{3}{*}{ Spring } & $b$ & 0.25 & $0.79^{*}$ & 0.02 & 0.15 & 0.52 & -0.43 & 0.35 \\
\hline & $Z$ & 0.81 & $2.08^{*}$ & -0.01 & 0.77 & 1.6 & -0.73 & 1.6 \\
\hline & $\beta(\mathrm{mm} / 10 \mathrm{a})$ & 1.81 & 7.73 & -0.03 & 2.48 & 5.43 & -3.23 & 3.45 \\
\hline \multirow{3}{*}{ Summer } & $b$ & $-0.93^{*}$ & -0.35 & -0.99 & -0.57 & -0.43 & -2.37 & 0.58 \\
\hline & $Z$ & $-2.01^{*}$ & -0.88 & $-2.16^{*}$ & -0.95 & -0.78 & $-2.31^{*}$ & -1.8 \\
\hline & $\beta(\mathrm{mm} / 10 \mathrm{a})$ & -8.71 & -4.97 & -9.02 & -4.66 & -4.14 & -35.08 & -8 \\
\hline \multirow{3}{*}{ Autumn } & $b$ & 0.01 & -0.37 & -0.08 & -0.38 & -0.61 & -1.10 & -0.36 \\
\hline & $Z$ & 0.42 & -0.69 & 0.3 & -0.81 & -1.51 & -1.19 & -1.11 \\
\hline & $\beta(\mathrm{mm} / 10 \mathrm{a})$ & 1.03 & -2.63 & 0.77 & -2.75 & -5.9 & -9.11 & -3.6 \\
\hline \multirow{3}{*}{ Winter } & $b$ & 0 & 0.04 & 0.01 & 0.02 & 0.10 & 0.07 & 0.05 \\
\hline & $Z$ & 0.37 & 0.66 & 0 & 0.05 & 1.31 & 0.45 & 0.67 \\
\hline & $\beta(\mathrm{mm} / 10 \mathrm{a})$ & 0.01 & 0.05 & 0 & 0 & 0.09 & 0.06 & 0.04 \\
\hline \multirow{3}{*}{ Annual } & $b$ & -0.67 & 0.11 & -1.03 & -0.84 & -0.43 & -3.83 & -0.56 \\
\hline & Z & -1.22 & 0.39 & -1.63 & -0.7 & -0.22 & $-2.57^{*}$ & -0.83 \\
\hline & $\beta(\mathrm{mm} / 10 \mathrm{a})$ & -7.13 & 2.27 & -10 & -4.44 & -2.04 & -50.96 & -4.47 \\
\hline
\end{tabular}

*The significant values at $5 \%$ significance level.

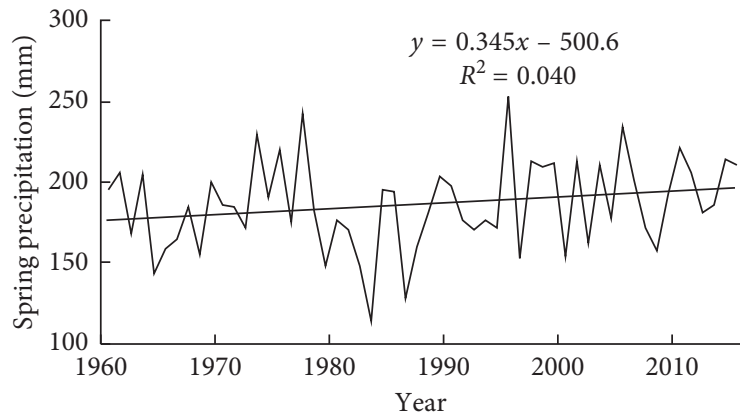

(a)

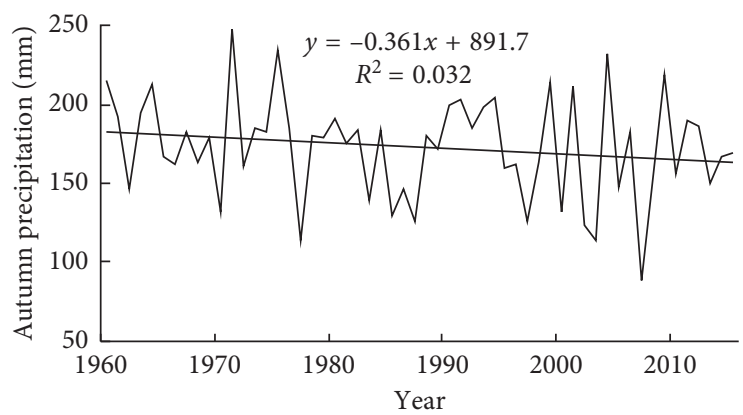

(c)

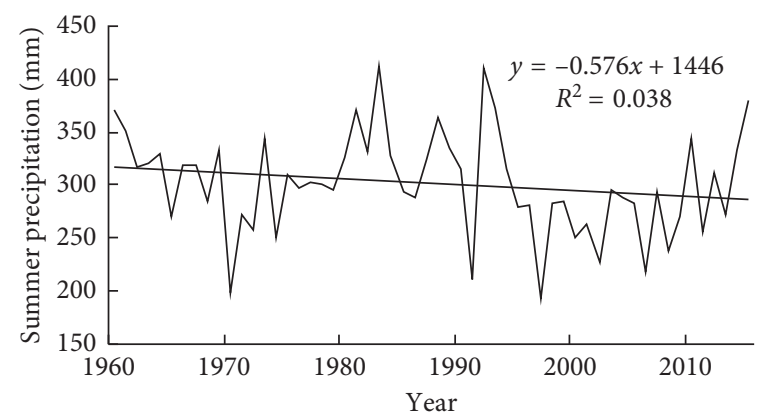

(b)

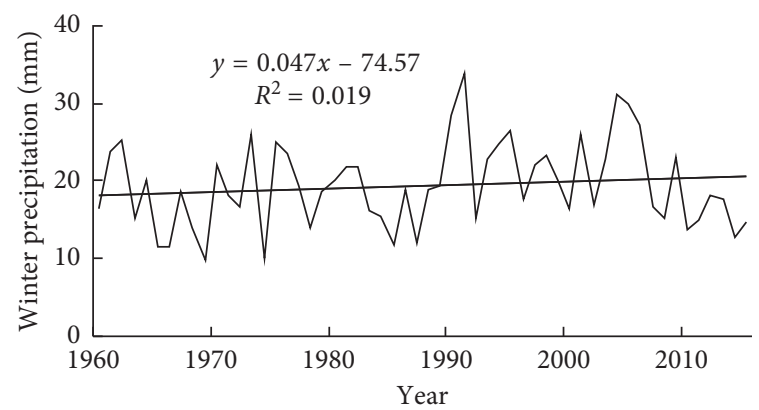

(d)

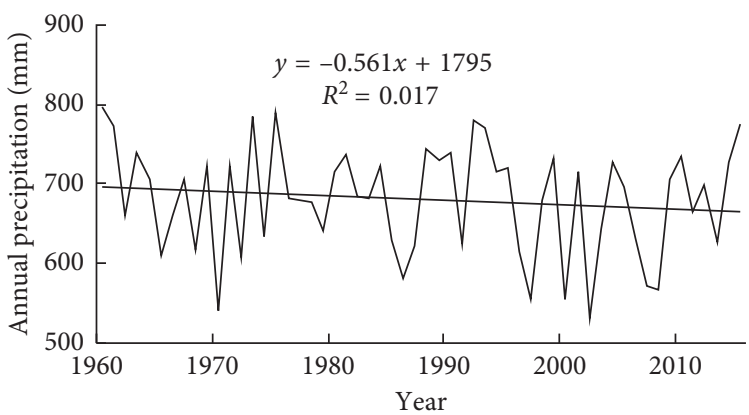

(e)

Figure 5: Trends of study area for seasonal and annual precipitation by liner regression method. 


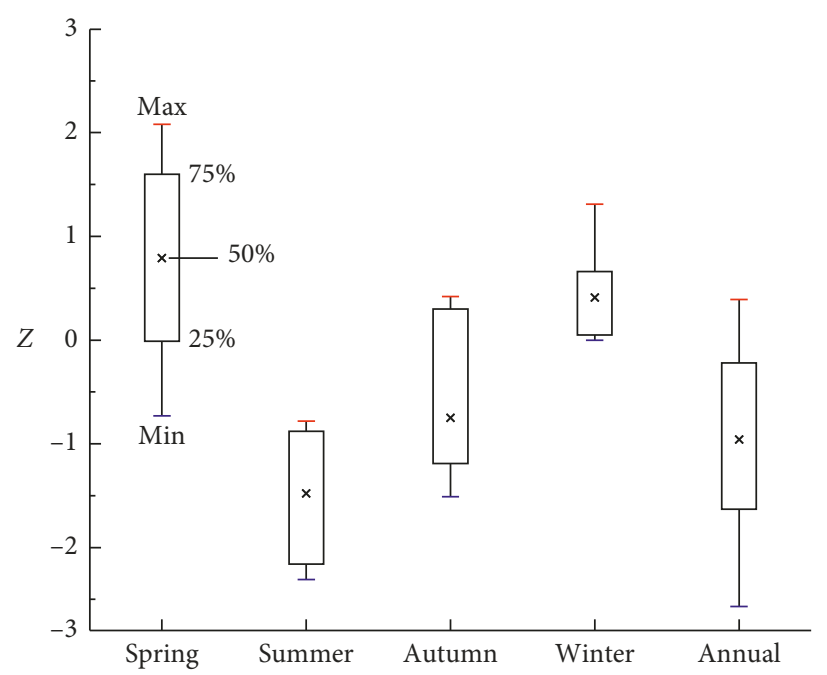

Figure 6: Box diagram of $Z$ at 6 stations in UMR for 1960-2015.

TABLE 4: Abrupt change points of precipitation time series.

\begin{tabular}{|c|c|c|c|c|c|c|c|}
\hline Region or station & Maoxian & Songpan & Wenchuan & Lixian & Heishui & Zipingpu & UMR \\
\hline Spring & 1988 & $\mathrm{~N}$ & $\mathrm{~N}$ & 1994 & 1994 & 1985 & $\mathrm{~N}$ \\
\hline Summer & 1990 & 1994 & 1993 & 1995 & 1994 & 1981 & 1994 \\
\hline Autumn & $\mathrm{N}$ & 1984 & $\mathrm{~N}$ & $\mathrm{~N}$ & 1975 & $\mathrm{~N}$ & 1976 \\
\hline Winter & $\mathrm{N}$ & $\mathrm{N}$ & $\mathrm{N}$ & $\mathrm{N}$ & 1987 & 1981 & $\mathrm{~N}$ \\
\hline Annual & 1995 & $\mathrm{~N}$ & $\mathrm{~N}$ & $\mathrm{~N}$ & 1995 & 1981 & 1995 \\
\hline
\end{tabular}

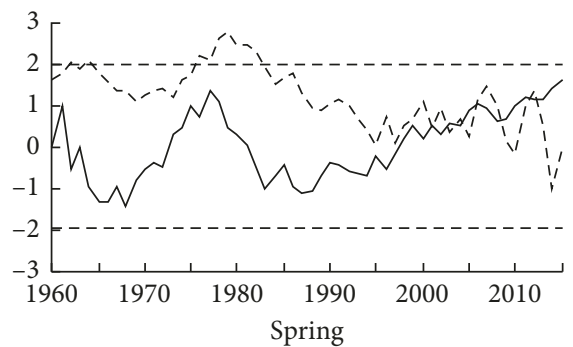

- UF

- - UB

(a)

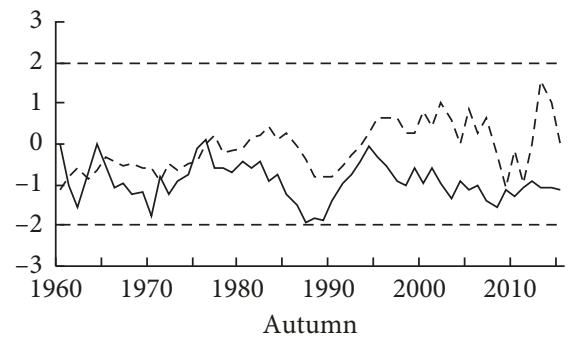

$-\mathrm{UF}$

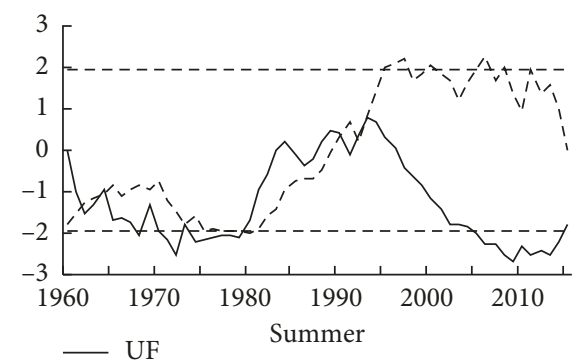

-- UB

(b)

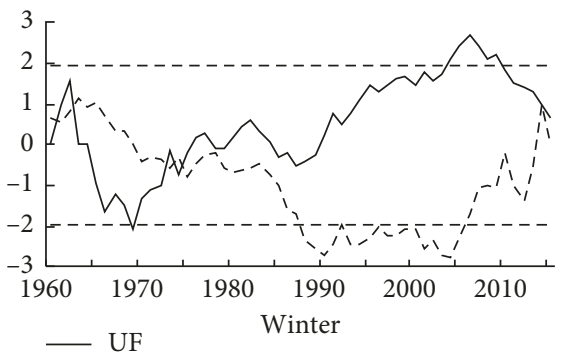

-- UB

(c)

(d)

Figure 7: Continued. 


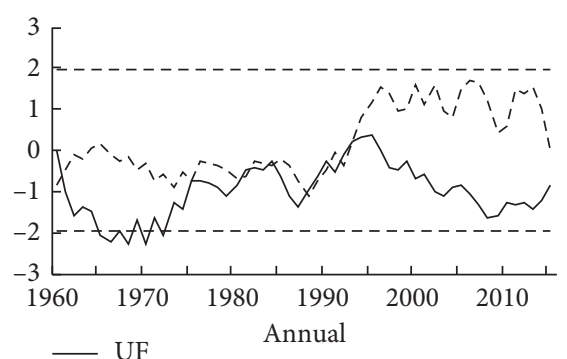

$---\mathrm{UB}$

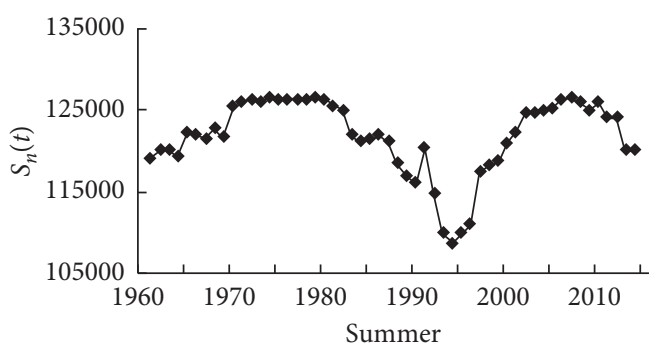

(g)

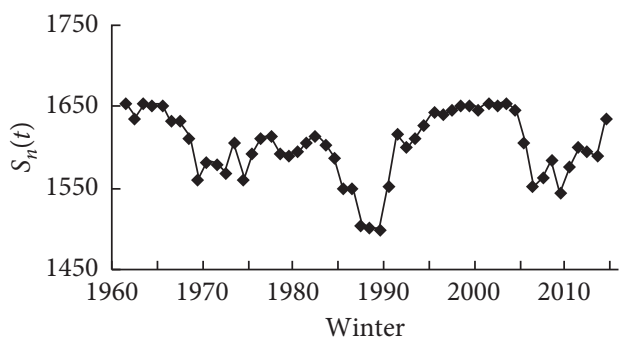

(i)

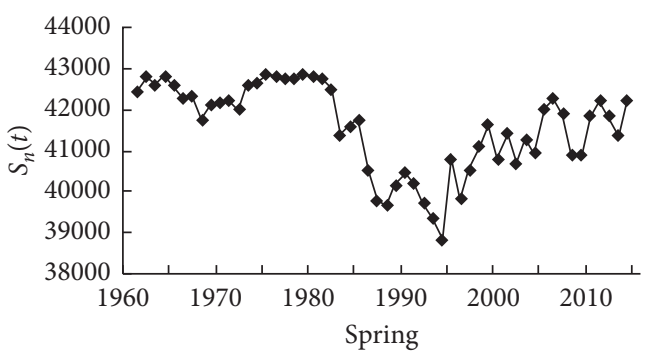

(f)

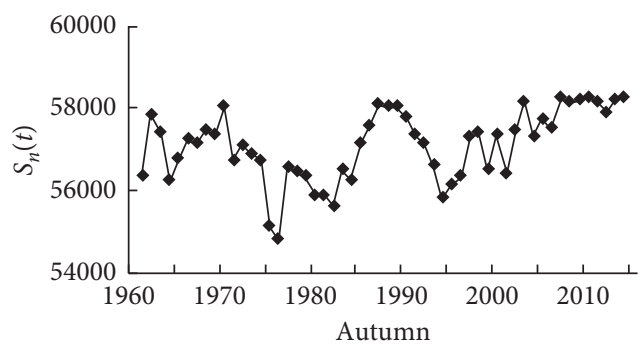

(h)

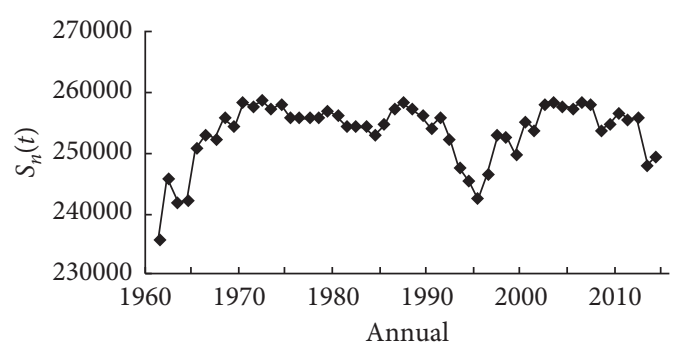

(j)

FIGURE 7: Change point diagnosed graphs by Mann-Kendall test of abrupt (a-e) and sequential cluster analysis (f-j) in the UMR. Horizontal dashed lines denote the confidence at level of 0.05 .

TABLE 5: Periods of precipitation time series.

\begin{tabular}{lccccccc}
\hline Region or station & Maoxian & Songpan & Wenchuan & Lixian & Heishui & Zipingpu & UMR \\
\hline Spring & $2,5,15$ & 4,19 & $4,7,17,24$ & $2,4,9,15$ & $2,4,21$ & $4,7,17$ & $2,4,19$ \\
Summer & $2,7,13$ & $2,6,9$ & 2,17 & 3,11 & 5,15 & $3,5,17$ & 5 \\
Autumn & $2,4,10,20$ & $2,5,9,15$ & $2,4,6,11,20$ & $2,10,18$ & $5,9,16$ & 4,16 & $2,5,10,17$ \\
Winter & $4,11,23$ & $3,5,14$ & $4,9,15$ & $4,7,16$ & $3,5,14$ & $3,6,15$ \\
Annual & $3,11,18$ & $2,5,9,18$ & $3,7,12,18$ & $4,11,15$ & $2,5,16$ & $3,5,17$ & $2,5,15$ \\
\hline
\end{tabular}

4 , and 19 years in spring; 5 years in summer; $2,5,10$, and 17 years in autumn; 3 and 15 years in winter. The detailed information of periods at gauging stations is no longer elaborated. In conclusion, the almost periods of study area were generally 2-5 years, 7-11 years, and 15-20 years [28].

4.5. Cause of Precipitation Change. Global warming is the background factor that influences the precipitation variation in the UMR. Over the twentieth century, especially since the 1990s, continuously increasing concentration of atmospheric carbon dioxide is resulting in global warming. Higher average air temperatures result in higher evaporation rates, higher water vapor contents, and consequently an accelerated hydrologic cycle. An important consequence of global warming is increased atmospheric moisture levels, thunderstorm activity, and/or large-scale storm activity. In the context of global warming, the precipitation pattern has changed in the UMR, which is influenced by atmospheric circulations, altitude, and anthropic activities.

The large-scale atmospheric circulation leads to the variation of precipitation over the UMR [40,42,43]. The advance and retreat of East Asian summer monsoon determine to a large extent the timing of the precipitation season and the amount of precipitation [44]. Other special monsoon-like circulations, such as the western Pacific subtropical high, Somali jet, and tropical cyclones, together with a blocking high and low trough in the mid-high 


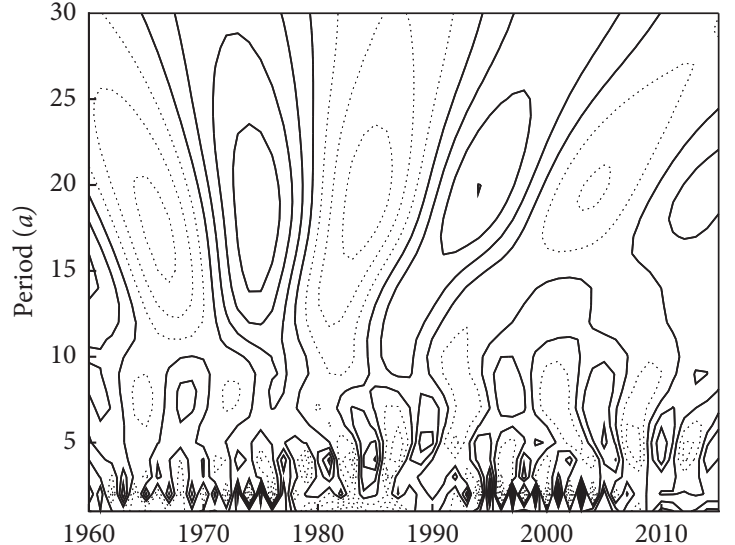

(a)

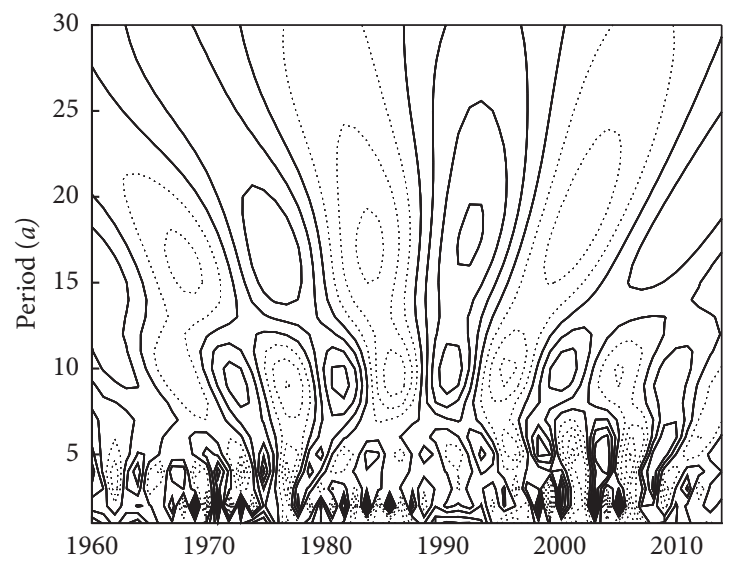

(c)

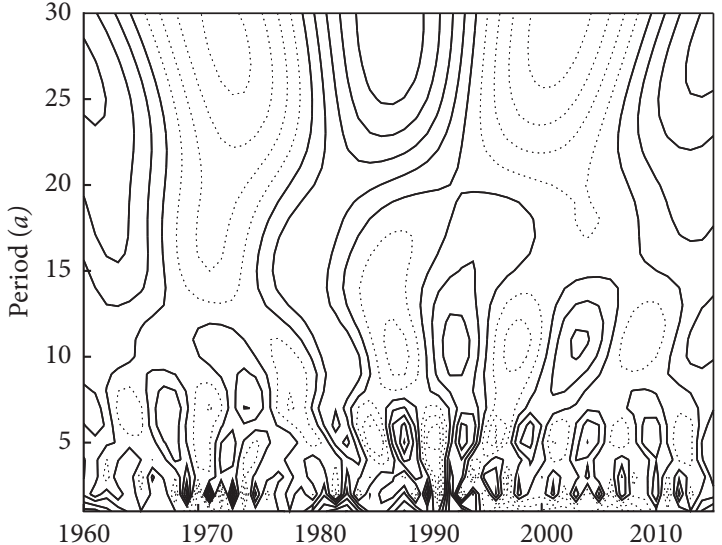

(b)

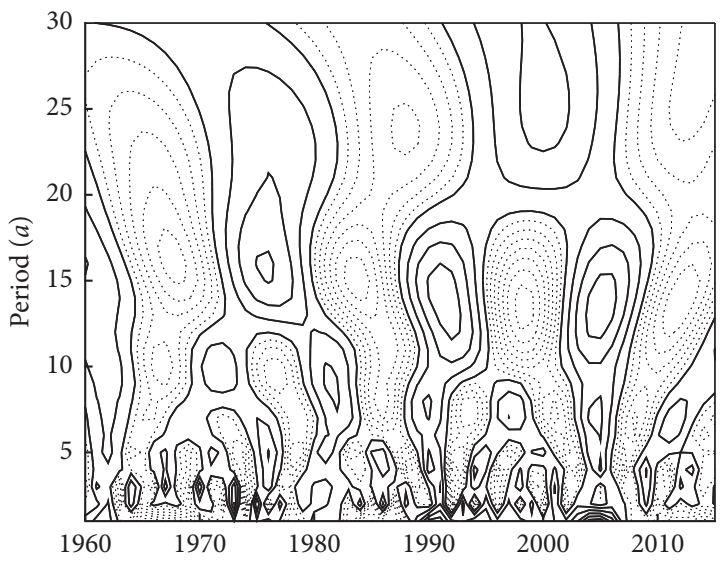

(d)

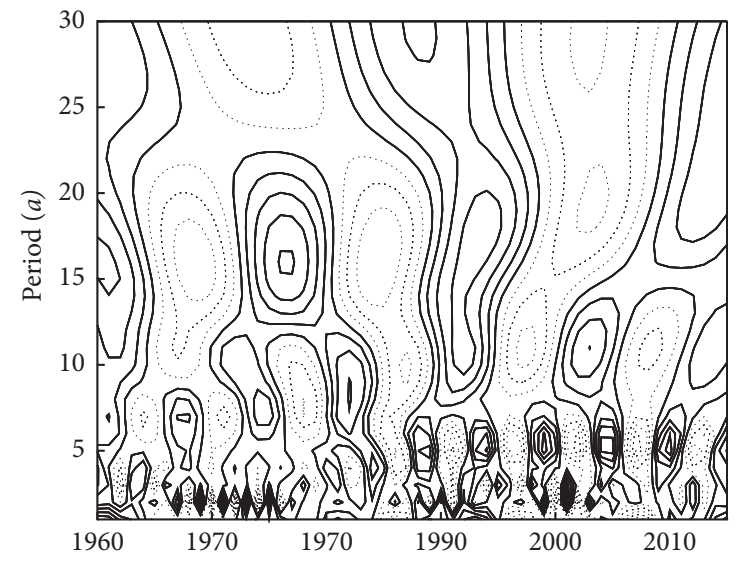

(e)

FIgURE 8: Time frequency graphs of wavelet transform in the UMR.

latitudes, also play active roles in precipitation variation over the study area [45].

Altitude is another cause of precipitation variation [46]. The statistic $Z$ value of annual precipitation has a good relationship with altitude, and the correlation coefficients are 0.99 (Figure 9). That is, the increasing trend of precipitation is relatively obvious at higher altitude, while the decreasing trend is more significant at low-altitude stations. On the whole, the $Z$ values in UMR increased with altitude, which is in accordance with the previous studies [47].

Some considerations show that the influence of anthropic activities on precipitation is robust [48]. Anthropic activities not only modify the exchange of heat, water, and momentum between the land surface and overlying atmosphere but also change the composition of the atmosphere over urban areas. Land use change driven by anthropic 


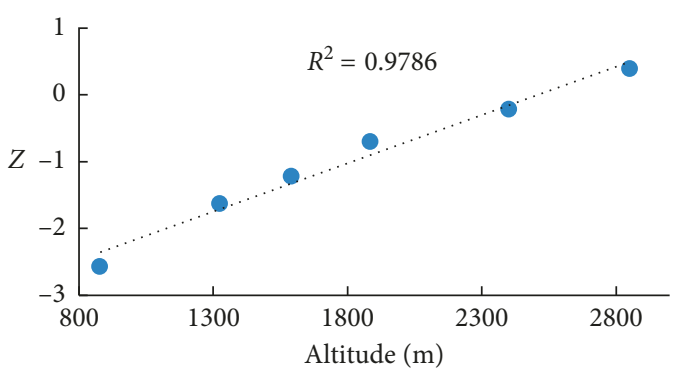

Figure 9: Relationships between the statistic $Z$ value of annual precipitation and altitude.

activities influences the local hydrometeorological processes and sometimes affects the precipitation significantly.

The physics mechanisms of precipitation variation are a challenge to deeply understand. Further investigation of the multiscale interaction among the atmospheric circulation, altitude, and anthropic activities may also be important and essential to understand the precipitation variation.

\section{Conclusion}

In this study, space-time distribution characteristics, trends, abrupt changes, and periods of annual and seasonal precipitation series in the UMR are analyzed during 1960-2015. According to the above analysis, the main conclusions are summarized as follows.

Distribution of precipitation is uneven in space, with more in the south and less in the southeast. The interannual variation of precipitation showed a clear regional and seasonal difference in the UMR. The decade average precipitation reached the lowest in the 2000s at all gauging stations and UMR and increased during 2010-2015. A preliminary conclusion was drawn that the precipitation in the study area was relatively abnormal after the 21st century.

Areal annual precipitation exhibited an insignificant decreasing trend from 1960 to 2015, which was mainly attributable to decreased summer precipitation. Spring precipitation exhibited an insignificant increasing trend, and winter precipitation remained unchanged.

The change points mainly appeared in 1980s and 1990s. And the almost periods of study area were generally $2-5$ years, 7-11 years, and 15-20 years. Due to the different natural topography, geographical location, and anthropic activities at the gauging stations, the different stations show different results of abrupt changes and periods.

Under the background of global warming, the precipitation variation of the UMR is influenced by atmospheric circulations, altitude, and anthropic activities. The increasing trend of annual precipitation is relatively obvious at higher altitudes, while the decreasing trend is more significant at low altitude stations. Further analysis is needed to quantitatively and systematically investigate the interactions among atmospheric circulations, altitude, and anthropic activities. Related research will provide scientific theoretical basis for water issues under climate change and help us to improve areal hazard mitigation and water resources management.

\section{Data Availability}

Most of the data series used to support the findings of this study is collected from the China Meteorological Data Sharing Service System, which is available on the web at http://data.cma.cn/. Only the data series at Zipingpu Station is supplied from the Bureau of Hydrology and Water Resources of Sichuan Province and cannot be made freely available.

\section{Conflicts of Interest}

The authors declare that they have no conflicts of interest.

\section{Acknowledgments}

This research was supported by the National Science Foundation Committee of China (No. 51679155).

\section{References}

[1] T. J. Crowley, "Causes of climate change over the past 1000 years," Science, vol. 289, no. 5477, pp. 270-277, 2000.

[2] S. Piao, P. Ciais, Y. Huang et al., "The impacts of climate change on water resources and agriculture in China," Nature, vol. 467, no. 7311, pp. 43-51, 2010.

[3] M. A. Altieri and C. I. Nicholls, "The adaptation and mitigation potential of traditional agriculture in a changing climate," Climatic Change, vol. 140, no. 1, pp. 33-45, 2017.

[4] Y. Wang and F. Yan, "Regional differentiation and decadal change of precipitation in China in 1960-2010," Progress in Geography, vol. 33, no. 10, pp. 1335-1347, 2014.

[5] X. Xu, Z. Xuezhen, E. Dai, and W. Song, "Research of trend variability of precipitation intensity and their contribution to precipitation in China from 1961 to 2010," Geographical Research, vol. 33, no. 7, pp. 1335-1347, 2014, in Chinese.

[6] G. Ren, Y. Zhan, Y. Ren et al., "Spatial and temporal patterns of precipitation variability over mainland China: I: climatology," Advances in water science, vol. 26, no. 3, pp. 299-310, 2015, in Chinese.

[7] T. Partal and E. Kahya, "Trend analysis in Turkish precipitation data," Hydrological Processes, vol. 20, no. 9, pp. 2011-2026, 2006.

[8] H. Chang and W. T. Kwon, "Spatial variations of summer precipitation trends in South Korea, 1973-2005," Environmental Research Letters, vol. 2, no. 4, article 045012, 2007.

[9] M. Ellouze, C. Azri, and H. Abida, "Spatial variability of monthly and annual rainfall data over Southern Tunisia," Atmospheric Research, vol. 93, no. 4, pp. 832-839, 2009.

[10] B. C. Bates, R. E. Chandler, and A. W. Bowman, "Trend estimation and change point detection in individual climatic series using flexible regression methods," Journal of Geophysical Research, vol. 117, no. D16, 2012.

[11] H.-J. Chu, T.-Y. Pan, and J.-J. Liou, "Change-point detection of long-duration extreme precipitation and the effect on hydrologic design: a case study of south Taiwan," Stochastic Environmental Research and Risk Assessment, vol. 26, no. 8, pp. 1123-1130, 2012.

[12] G. D. Martino, N. Fontana, G. Marini, and V. P. Singh, "Variability and trend in seasonal precipitation in the 
continental United States," Journal of Hydrologic Engineering, vol. 18, no. 6, pp. 630-640, 2013.

[13] Y. Wu, W. Wang, and G. Wang, "Detecting variation trends of temperature and precipitation for the Dadu River Basin, China," Advances in Meteorology, vol. 2016, Article ID 2564586, 11 pages, 2016.

[14] S. K. Chandniha, S. G. Meshram, J. F. Adamowski, and C. Meshram, "Trend analysis of precipitation in Jharkhand State, India," Theoretical and Applied Climatology, vol. 130, no. 1-2, pp. 261-274, 2017.

[15] J. H. Sung, E.-S. Chung, Y. Kim, and B.-R. Lee, "Meteorological hazard assessment based on trends and abrupt changes in rainfall characteristics on the Korean peninsula," Theoretical and Applied Climatology, vol. 127, no. 1-2, pp. 305-326, 2017.

[16] M. Sayemuzzaman and M. K. Jha, "Seasonal and annual precipitation time series trend analysis in North Carolina, United States," Atmospheric Research, vol. 137, no. 2, pp. 183-194, 2014.

[17] A. Shirvani, "Change point detection of the Persian Gulf sea surface temperature," Theoretical and Applied Climatology, vol. 127, no. 1-2, pp. 123-127, 2017.

[18] M. Zarenistanak, A. G. Dhorde, and R. H. Kripalani, “Trend analysis and change point detection of annual and seasonal precipitation and temperature series over southwest Iran," Journal of Earth System Science, vol. 123, no. 2, pp. 281-295, 2014.

[19] A. K. Mishra, M. Özger, and V. P. Singh, "Wet and dry spell analysis of global climate model-generated precipitation using power laws and wavelet transforms," Stochastic Environmental Research and Risk Assessment, vol. 25, no. 4, pp. 517-535, 2011.

[20] A. Araghi, M. Mousavi Baygi, J. Adamowski, J. Malard, D. Nalley, and S. M. Hasheminia, "Using wavelet transforms to estimate surface temperature trends and dominant periodicities in Iran based on gridded reanalysis data," Atmospheric Research, vol. 155, pp. 52-72, 2015.

[21] N. Joshi, D. Gupta, S. Suryavanshi, J. Adamowski, and C. A. Madramootoo, "Analysis of trends and dominant periodicities in drought variables in India: a wavelet transform based approach," Atmospheric Research, vol. 182, pp. 200-220, 2016.

[22] S. Jemai, M. Ellouze, H. Abida et al., "Variability of precipitation in arid climates using the wavelet approach: case study of watershed of gabes in South-East Tunisia," Atmosphere, vol. 8, no. 12, pp. 178-193, 2017.

[23] Y.-F. Sang, D. Wang, J.-C. Wu, Q.-P. Zhu, and L. Wang, "Improved continuous wavelet analysis of variation in the dominant period of hydrological time series," Hydrological Sciences Journal, vol. 58, no. 1, pp. 118-132, 2013.

[24] L. Zongxing, Y. He, P. Wang et al., "Changes of daily climate extremes in southwestern China during 1961-2008," Global and Planetary Change, vol. 80-81, pp. 255-272, 2012.

[25] P. Li and X. Zhao, "Analysis on the precipitation anomalies in southwest of China from 2009 to 2011," Acta Scientiarum Naturalium Universitatis Pekinensis, vol. 49, no. 6, pp. 1083-1097, 2013, in Chinese.

[26] L. Kang, S. Liu, and X. Liu, "Multiresolution and periodicity analysis of hydrological and meteorological factors in upper reaches of Minjiang River," ActaEcologica Sinica, vol. 36, no. 5, pp. 1253-1262, 2016, in Chinese.

[27] X. Huang, J. Zhao, W. Li, and H. Jiang, "Impact of climatic change on streamflow in the upper reaches of the Minjiang
River, China," Hydrological Sciences Journal, vol. 59, no. 1, pp. 154-164, 2014.

[28] D. Zhou, M. Zhang, X. Yu, and Y. Liu, "Spatial and temporal characteristics of precipitation in Minjiang River basin in flood period," Journal of China Hydrology, vol. 29, no. 4, pp. 26-29, 2009.

[29] S. Ma, Y. Cao, Z. Zhang, and Y. Zhen, "Climatic change tendency and mutation analysis of song Pan county, the source of Minjiang River," Journal of Chengdu University of Information Technology, vol. 32, no. 5, pp. 550-553, 2017.

[30] C. W. Landsea and W. M. Gray, "The strong association between western sahelian monsoon rainfall and intense Atlantic Hurricanes," Journal of Climate, vol. 5, no. 5, pp. 435-453, 1992.

[31] S. G. Meshram, V. P. Singh, and C. Meshram, "Long-term trend and variability of precipitation in Chhattisgarh State, India," Theoretical and Applied Climatology, vol. 129, no. 3-4, pp. 729-744, 2016.

[32] H. B. Mann, "Nonparametric test against trend," Econometrica, vol. 13, no. 3, pp. 245-259, 1945.

[33] M. G. Kendall, Rank Correlation Methods, Charles Graffin, London, UK, 1975.

[34] L. Liang, L. Li, and Q. Liu, "Precipitation variability in northeast China from 1961 to 2008," Journal of Hydrology, vol. 404, no. 1-2, pp. 67-76, 2011.

[35] C. Hu, Y. Xu, L. Han, L. Yang, and G. Xu, "Long-term trends in daily precipitation over the Yangtze River delta region during 1960-2012, Eastern China," Theoretical and Applied Climatology, vol. 125, no. 1-2, pp. 131-147, 2016.

[36] Y. Chen, L. U. Baohong, Y. Zhang, and X. Zhou, "Improvement of sequential cluster Analysis method for extracting turning point of time series," Journal of China Hydrology, vol. 31, no. 1, pp. 41-44, 2011, in Chinese.

[37] D. Li, W. Wang, S. Hu, and Y. Li, "Characteristics of annual runoff variation in major rivers of China," Hydrological Processes, vol. 26, no. 19, pp. 2866-2877, 2012.

[38] S. Wang, S. Jiao, and H. Xin, "Spatio-temporal characteristics of temperature and precipitation in sichuan province, southwestern China, 1960-2009," Quaternary International, vol. 286, pp. 103-115, 2013.

[39] S. Huang, W. Zang, M. Xu et al., "Study on runoff simulation of the upstream of Minjiang River under future climate change scenarios," Natural Hazards, vol. 75, no. S2, pp. 139-154, 2015.

[40] Y. Zhu and R. Yu, "Interannual variation of summer precipitation in the west of Sichuan basin and its relationship with large-scale circulation," Chinese Journal of Atmospheric Sciences, vol. 27, no. 6, pp. 10445-11056, 2003, in Chinese.

[41] H. Du and S. He, "The analysis on characteristics of precipitation and trends in drought and flood disasters in Minjiang River Basin," Research of Soil and Water Conservation, vol. 22, no. 1, pp. 153-157, 2015.

[42] Y. Hu, P. Zhai, L. Liu, Y. Chen, and Y. Liu, "Dominant largescale Atmospheric circulation systems for the extreme precipitation over the western Sichuan basin in summer 2013," Advances in Meteorology, vol. 2015, Article ID 690363, 10 pages, 2015.

[43] Y. Huang and X. Cui, "Moisture sources of an extreme precipitation event in Sichuan, China, based on the Lagrangian method," Atmospheric Science Letters, vol. 16, no. 2, pp. 177-183, 2015.

[44] B. Chen and X.-D. Xu, "Spatiotemporal structure of the moisture sources feeding heavy precipitation events over the 
Sichuan Basin," International Journal of Climatology, vol. 36, no. 10, pp. 3446-3457, 2015.

[45] F. Liang, S. Tao, J. Wei, and C. Bueh, "Variation in summer rainfall in North China during the period 1956-2007 and links with atmospheric circulation," Advances in Atmospheric Sciences, vol. 28, no. 2, pp. 363-374, 2011.

[46] H. Yu, L. Wang, R. Yang, M. Yang, and R. Gao, “Temporal and spatial variation of precipitation in the Hengduan Mountains region in China and its relationship with elevation and latitude," Atmospheric Research, vol. 213, pp. 1-16, 2018.

[47] W. Zeng, Z. Yu, S. Wu, and J. Qin, "Changes in annual, seasonal and monthly precipitation events and their link with elevation in Sichuan province, China," International Journal of Climatology, vol. 36, no. 5, pp. 2303-2322, 2015.

[48] X. Zhang, F. W. Zwiers, G. C. Hegerl et al., "Detection of human influence on twentieth-century precipitation trends," Nature, vol. 448, no. 7152, pp. 461-465, 2007. 

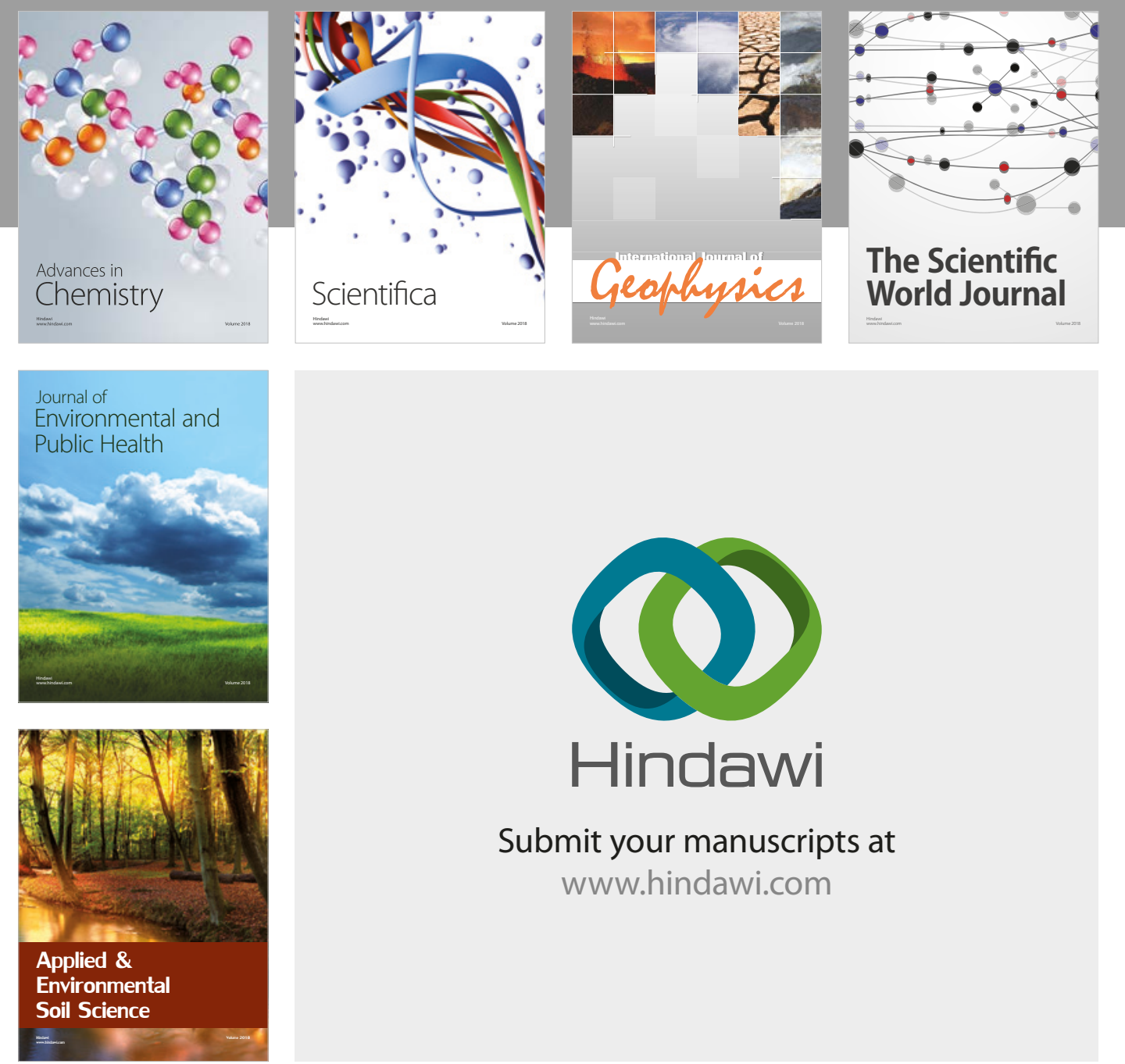

The Scientific

\section{World Journal}
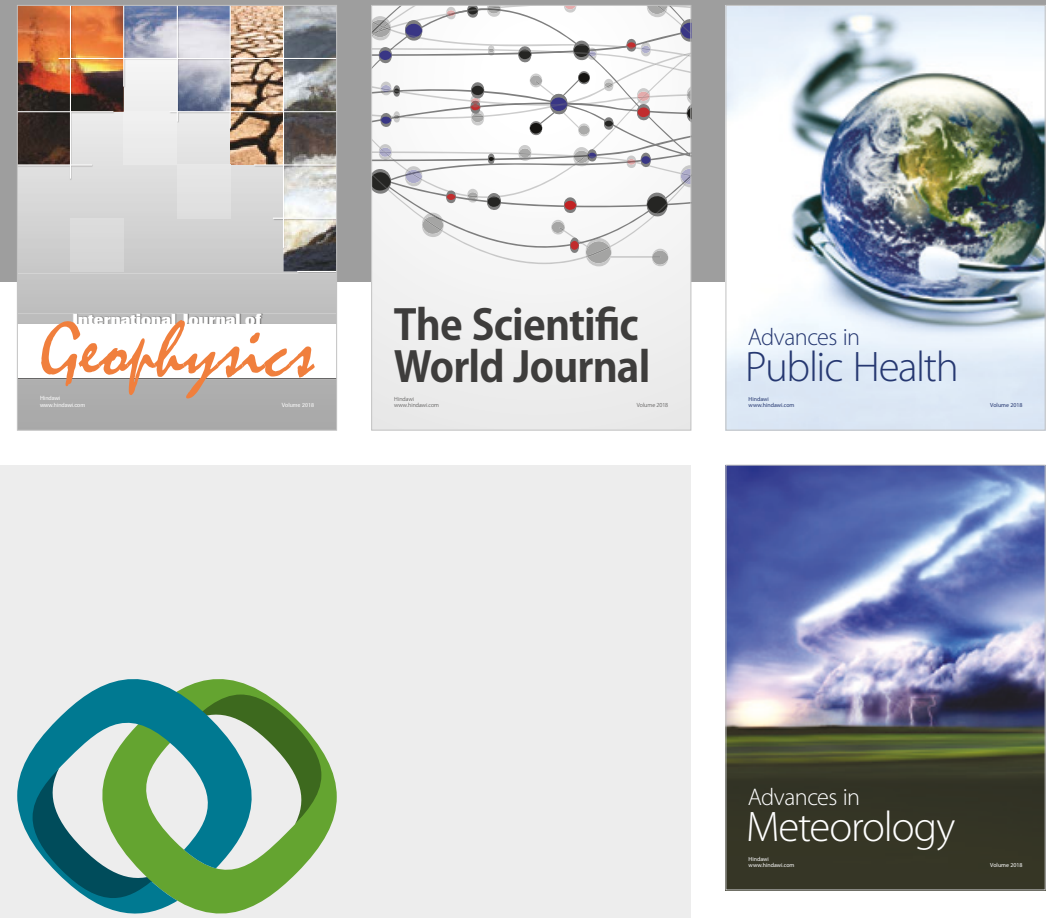

Advan

Public Health

\section{Hindawi}

Submit your manuscripts at

www.hindawi.com
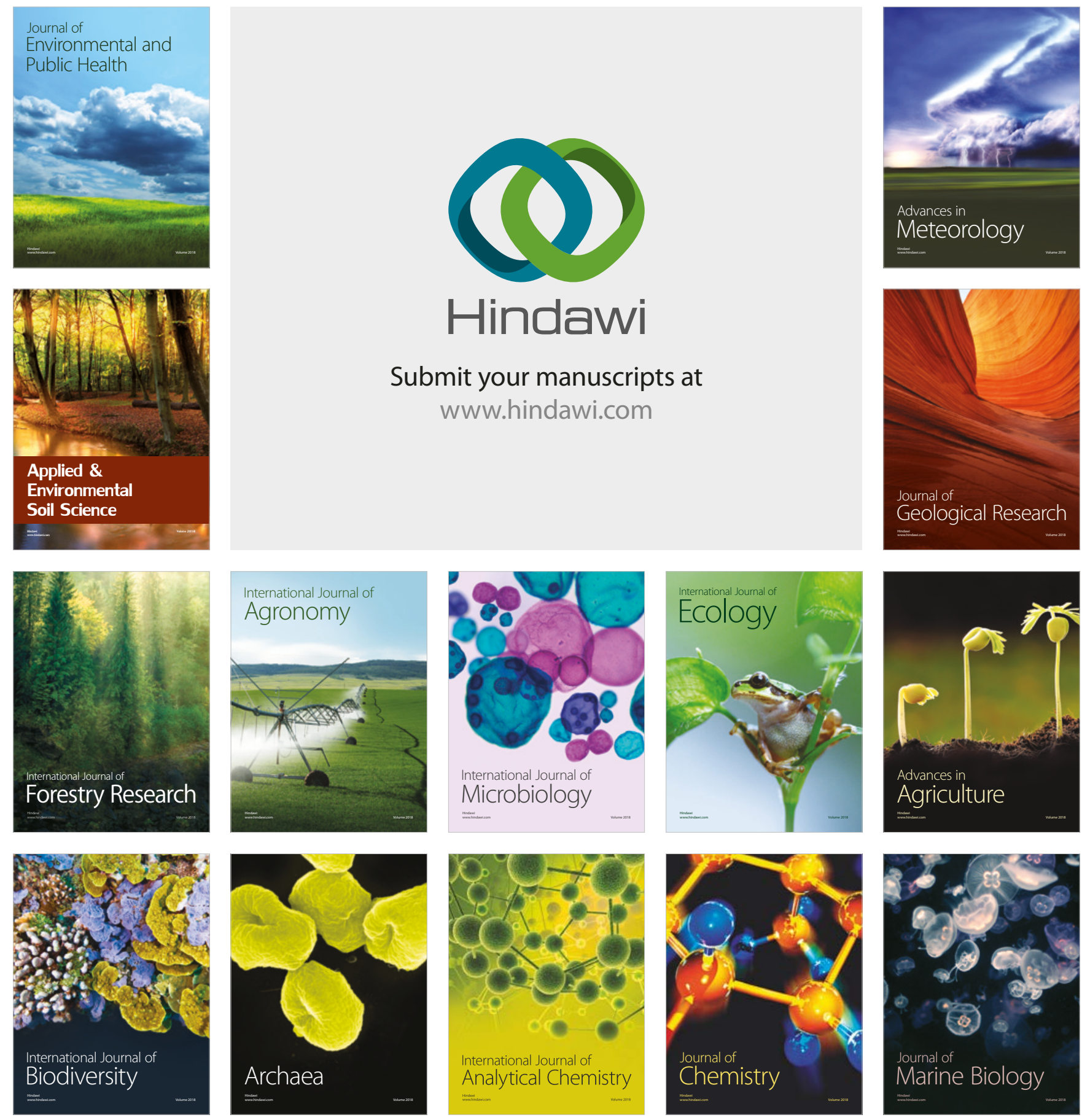